\title{
Boosting critical thinking in a Project Management course: An active learning experience
}

\author{
Berbegal-Mirabent, Jasmina ${ }^{a}$; Gil-Doménech, Dolors ${ }^{a}$ and Gieure, Clara ${ }^{b}$ \\ ${ }^{a}$ Department of Economy and Business Organization, Universitat Internacional de \\ Catalunya, Spain, ${ }^{\mathrm{b}}$ Department of Education, Universidad Católica de Valencia, Spain.
}

\begin{abstract}
The present study reports the experience of a project-based activity in which students are asked to plan an event. It is part of a Project Management course taught at Universitat Internacional de Catalunya, in a Masters' Degree in Business Administration and Production Systems. The activity has been designed in such a way that it is expected to help students develop the acquired technical skills while it requires the use of different quantitative methods and tools to interpret data for decision-making.

The results show that active learning materialized in the form of projectbased activities make courses more enjoyable for both instructors and students, and most importantly, contribute to develop students' skills such as teamwork and critical thinking. However, while it is useful for students to gain some exposure to the material through pre-class readings and overview lectures, students do not fully understand and realize about their importance until they actively take part and reflect on the meaning of what they are learning.
\end{abstract}

Keywords: Active learning; Rubrics; Critical thinking; Project management 


\section{Introduction}

Organizations use project-based methods to accomplish tasks. A project is a temporary endeavor undertaken to create a unique product, service or result. It is temporary in that it has a defined beginning and end in time, and therefore a defined scope and resources. Delivering complex projects on time and under budget constraints is a daily challenge.

Education programs and especially those designed for engineering management are now adjusting their teaching methodologies so that students learn how to plan and evaluate a project, competencies that will be required in their professions. In this respect, there are several voices that claim that teaching methods should include active learning methods in which students adopt a leading role (Ayaz \& Söylemez, 2015). Project-based activities respond to this typology of teaching methods and are found to lead to better academic results. Particularly, Fruchter (2001) expresses the usefulness of introducing projects in engineering programs, since they help to improve and broaden students' skills. Furthermore, project-based activities engage students in the investigation of authentic problems ( Kubiatko \& Vaculová, 2011).

In this context, this study reports the experience of a project-based activity in which students are asked to plan an event. The project activity is designed in such a way that it is expected to help students develop the acquired technical skills while it requires the use of different quantitative methods and tools to interpret data for decision-making. This activity is part of a Project Management course taught at Universitat Internacional de Catalunya, in a Masters' Degree in Business Administration and Production Systems.

\section{Theoretical underpinnings}

With the rapid advancements and requirements of our society, universities have had to adapt their ways of teaching by shifting their focus on preparing students for their future careers. Higher education has to ensure students acquire skills that can be transferred to other fields (Ruizacárate Varela, García-García, González-García, \& Casado-Sánchez, 2013). The application of new teaching methodologies based on skill development provides students an invaluable lifelong learning (Kember, 2009). Following this line, in engineering related programs educators have concentrated on providing students with tools that increase the effectiveness of presentations and writings, boost critical thinking, promote the use of new technologies, enhance team working and facilitate the management of projects (Pulko $\&$ Parikh, 2003).

The necessity of new teaching practices has changed the traditional lecturing at universities, formerly centered on teaching for "knowing-what", to an active learning methodology, with a focus on teaching for "knowing-why" (Fruchter, 2001). Active learning consists of involving students in the learning process, making them participate in activities that 
improve their performance during and after the course, thus bolstering their skills (Bell \& Kozlowski, 2008). This student-centered approach makes learners more independent and responsible, but they are also accompanied by the educator in their striving for solutions (Doppelt, 2003). The positive effects of active learning activities, such as higher academic results, motivation to learn, and a deeper understanding of the content, have been proved in a number of studies (Michael, 2006).

In order to implement an active learning methodology there is a wide variety of activities that can be used. Projects are considered some of the most relevant ones (Friedman, 2000). Project-based learning (PBL) activities make students find solutions for real problems, facilitating the acquisition of skills that can be later used in real-life situations, such as teamwork, critical thinking, and communication skills (Macho-Stadler \& Elejalde-García, 2013). For a proper consecution of the project, students need to learn how to communicate and organize the tasks to do and how to collaborate with others following a series of specifications. To sum up, PBL results in an experience that boosts not only students' skills but also their autonomy and responsibility (Kubiatko \& Vaculová, 2011).

Considering the benefits of the PBL, the activity described here consists in asking students to develop a project plan. While doing so they will be developing several skills: teamwork, as a tool that allows students to obtain better results than working alone (Cortez, Nussbaum, Woywood, \& Aravena, 2009; Michael, 2006); and critical thinking, which can serve as a mean to understand concepts needed for the correct consecution of the task.

\section{Description of the activity}

\subsection{Context}

Courses on project management provide students with the knowledge, tools and skills to manage projects in an efficient and organized way. The activity described here is part of a course on Project Management taught in the Master's Degree in Business Administration and Production Systems offered at Universitat Internacional de Catalunya. Consistent with the managerial perspective of the course, the course strives to provide a balance between a qualitative and an analytical-oriented approach. Accordingly, the teaching method combines theoretical and practical readings, simulations exercises and case studies, being the "Organization of an event" activity the main project in which students will work.

The experience reported in this paper was hold during the first semester of 2015/16 academic year, with a class size of 44 students. Master students that participated in this course came from different countries and had different educational backgrounds, mainly in the areas of business administration and engineering management. 


\subsection{Description of the activity}

The main objective of this activity is to develop a project plan. This assignment is designed to develop student's skills in actual applications requiring the use of different quantitative methods and tools in interpreting data for decision-making.

Students, working in groups of 5 or 6 , are asked to plan an event and assess its feasibility in terms of resources, costs, risks and impact. They should imagine that someone has hired them to organize an event (e.g. a conference, an exhibition, a concert, a workshop) where different stakeholders are going to be involved. This event (of their own choice) is scheduled in a two-month period. The project covers the following points: project scope, stakeholder analysis, work breakdown structure, project plan, project and cost scheduling, risk assessment, impact assessment, and general overview.

At the end of the project, each group should deliver the final report and give a 10 minutes oral presentation. The instructions of the project are given one month prior the final delivery. During this month, students will have 3-hours per week to work in the project in class and discuss its progress with the lecturer. The topic of the project (that is, the event to be organized) should be approved by the instructor.

\subsection{Assessment}

This activity contributes $30 \%$ to the final grade of the course on Project Management. The assessment takes into consideration three main aspects: class meetings (25\%), content $(50 \%)$, and the oral presentation $(25 \%)$.

Class meetings refer to the active participation of students in working in the project in class. Although all group members are expected to discuss regularly about the project, and must have equal participation in completing the group work, their engagement might be different. Accordingly, this score might not be the same for all the members of a group. The final report is limited to 25 pages. A 10 -minutes oral presentation is scheduled for the last day of class. Two members of each group would be presenting the work to the whole class. In order to ensure that all students have been involved in preparing the presentation, the lecturer appoints these students the same day of the presentation.

Both the report and the support material to be used during the presentation must be submitted through the online platform of the course one day prior to the oral defense. Failure to submit these documents on time will result in a penalty in the project grade.

In order to boost critical thinking students are given an evaluation sheet (in the form of a rubric) to self-evaluate their own work, in a scale form 1 (poor) to 5 (outstanding). This form should be submitted after the oral presentation is completed. Also, during the presentations, students are required to evaluate their classmates. The instructor also uses the same rubric to assess the projects (see Table 1). 
Table 1. Rubric to assess the content and the presentation.

\begin{tabular}{|c|c|c|c|}
\hline \multicolumn{3}{|c|}{ Criteria } & Description \\
\hline \multirow{5}{*}{$\begin{array}{l}\overrightarrow{0} \\
\stackrel{\overrightarrow{0}}{0}\end{array}$} & \multicolumn{2}{|c|}{ Event idea } & Original, interesting, well-justified \\
\hline & \multicolumn{2}{|c|}{ Feasibility } & Reasonable planning, budget and use of resources \\
\hline & \multicolumn{2}{|c|}{ Information } & Proper description on how to organize the event \\
\hline & \multicolumn{2}{|c|}{ Risk assessment } & Risk impact, contingency plan, control plan \\
\hline & \multicolumn{2}{|c|}{ Impact assessment } & Social and environmental \\
\hline \multirow{5}{*}{ 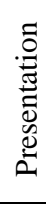 } & \multirow{2}{*}{ Design } & Slides & Creativity, originality, clarity, text font choice, style \\
\hline & & Structure & Logical sequence \\
\hline & \multirow{3}{*}{$\begin{array}{l}\text { Oral } \\
\text { defense }\end{array}$} & Non-verbal skills & Eye contact, body language, posture \\
\hline & & Verbal skills & Elocution, enthusiasm \\
\hline & & Comprehension & Subject knowledge \\
\hline
\end{tabular}

Two additional questions are included in the evaluation sheet. First, students should adopt the role of an investor and decide the two projects in which they would invest their money in order to execute the project. Second, students are encouraged to self-reflect and analyse in which degree each team member feels accountable and engaged with the project (how tasks were distributed) and their opinion with respect to the other team members.

\section{Results}

Figure 1 graphically illustrates the evaluations from classmates (in blue), the members of the group presenting (in red) and the lecturer (in green). From this figure it can be interfered that students tend to be more critical with others' work rather than with their own project. One explanation for this lies in the fact that students are evaluating others' work based on the oral presentations, while when evaluating themselves have the full picture of their work.

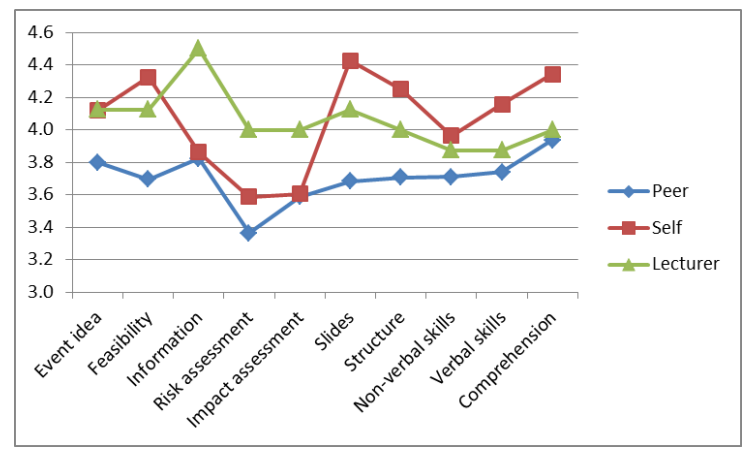

Figure 1. Comparison of the peer-, self-and lecturer's evaluation for each of the criterion.

It is noteworthy to point out that there are three criteria where lecturer's score were higher than self- and peer- evaluations. The rationale behind this may lay in the fact that the assessment of the lecturer was not only based on the information given in the presentation but also based on a careful reading of the full report. Because of the limited time allowed 
for presentations, students from other groups might find difficult to evaluate the cost structure, the risk assessment and the impact of the project.

When assessing their own work, results indicate that students are quite confident in terms of their verbal skills, knowledge on the topic as well as in the design of the support material for the presentation. Because during this course on Project Management students have to perform several presentations, results indicate that students have developed communication skills that help them presenting their work naturally in front of other people. This result is very important, as in their daily profession, project managers are constantly asked to lead meetings and negotiate with the different stakeholders involved in a project.

Following the rubric provided in Table 1, Figure 2 groups the items in three main dimensions: Content, Design and Oral defense. Results confirm the previous observations.

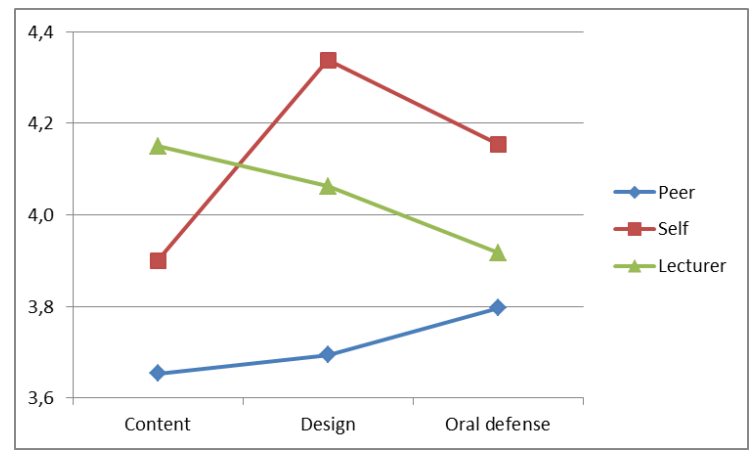

Figure 2. Comparison of the peer-, self-and lecturer's evaluation for main dimensions.

Grades from the items included in the rubric were then transformed into a 0-10 scale. The dimensions of "design" and "oral defense" were equally contributing (50\% each) to the "presentation" score. All students were also assigned with a "class meeting" grade which assessed their participation in class. Table 2 summarizes all the records.

Table 2. Rubric to assess the project and the presentation.

\begin{tabular}{|c|l|c|c|r|}
\hline Group & \multicolumn{1}{|c|}{ Topic } & $\begin{array}{c}\text { Content } \\
{[\mathbf{5 0 \%}}\end{array}$ & $\begin{array}{c}\text { Presentation } \\
{[\mathbf{2 5 \%}}\end{array}$ & $\begin{array}{c}\text { Class meetings* } \\
{[\mathbf{2 5 \%}]}\end{array}$ \\
\hline A & Basketball tournament & 9.2 & 8.5 & $8.5(0.55)$ \\
\hline B & Barcelona tour & 6.8 & 8.0 & $8.0(0.00)$ \\
\hline C & Bear pong competition & 8.0 & 8.8 & $10.0(0.00)$ \\
\hline D & Solidarity Racing for breast cancer's cure & 8.0 & 8.3 & $7.0(2.19)$ \\
\hline E & Food truck meeting & 8.0 & 7.3 & $8.0(1.41)$ \\
\hline F & University Day & 8.4 & 8.0 & $9.2(0.41)$ \\
\hline G & "Unplugged day" for Google employees & 8.6 & 8.0 & $9.0(0.00)$ \\
\hline H & Wine workshop & 7.6 & 6.8 & $7.6(1.95)$ \\
\hline
\end{tabular}

* Standard deviation in brackets 
We also analyzed the correlation between instructor's grades and the self-evaluations performed. Results indicate that there is no correlation ( $p$-value $=0.5727$ ).

With respect to the self-reflection questions, students show a high degree of satisfaction with the activity. They positively assess certain aspects such as the design of the activity, working in class and receiving the lecturer's orientation, the choice of two people for the oral presentation without previous advice, and the application of concepts learned in class. Students also appreciate having worked in teams, by organizing and dividing tasks in a balanced and fair way, and achieving a high degree of commitment with the project. They express having contributed to the proper consecution of the activity, acknowledging not only their tasks but also others' work. Most of the students also report having understood the importance and usefulness of activities such as the one described in this paper.

\section{Discussion and conclusions}

Active learning materialized in the form of project-based activities make courses more enjoyable for both instructors and students, and most importantly, contribute to develop students' skills such as teamwork and critical thinking. However, while it is useful for students to gain some exposure to the material through pre-class readings and overview lectures, students do not fully understand and realize about their importance until they actively take part and reflect on the meaning of what they are learning.

As for the specific experience described in this paper, although the activity has been demonstrated to be of great profit, from direct observation during the session and the feedback obtained from students there is still room for improvement. Particularly, it is possible to envisage some aspects that need to be considered in future editions. First, there is a need to consider the peer-assessment within the project's global mark. Second, it is recommended to introduce the project at the very beginning of the course, and, as the course progresses and the contents are presented in class, start working in the project. Lastly, we will include peer-assessment of the project's report, so that each group will be assigned to another project and would be expected to perform a critical review and elaborate a report with their comments.

Several challenges were also faced. On the one hand, the course enrolled a large number of students which impedes a sole instructor to fully gather all the concerns and feedback during the "class meeting" sessions. On the other hand, the course enrolled both engineering and business administration students which showed that business students needed more help as they were not used to project-based activities.

All in all, and based on our experience, we posit that project-based activities are useful for:

(i) embedding all the concepts of the course in a single integrative project; and (ii) developing critical thinking through the students' own work and peer-work. Therefore, we 
argue that there is an urgent need to introduce project-based activities at all levels, but particularly in master courses, where students are expected to be challenged with real (or simulated) cases, as they will be in the near future, when entering the marketplace.

\section{References}

Ayaz, M. F., \& Söylemez, M. (2015). The Effect of the Project-Based Learning Approach on the Academic Achievements of the Students in Science Classes in Turkey: A Meta-Analysis Study. Education and Science, 40(178), 255-283.

Bell, B. S., \& Kozlowski, S. W. J. (2008). Active learning: effects of core training design elements on self-regulatory processes, learning, and adaptability. The Journal of Applied Psychology, 93(2), 296-316.

Chase, C. C., \& Geldenhuys, K. M. (2008). Student-centred teaching in a large heterogeneous class. Medical Education, 35(11), 1071-1072.

Cortez, C., Nussbaum, M., Woywood, G., \& Aravena, R. (2009). Learning to collaborate by collaborating: a face-to-face collaborative activity for measuring and learning basics about teamwork. Journal of Computer Assisted Learning, 25(2), 126-142.

Doppelt, Y. (2003). Implementation and assessment of project-based learning in a flexible environment. International Journal of Technology and Design Education, 13(3), 255-272.

Friedman, K. (2000). Creating design knowledge: from research into practice. IDATER Conference, 1(September), 5-32.

Fruchter, R. (2001). Dimensions of Teamwork Education. International Journal of Engineering Education, 17(4\&5), 426-430.

Kember, D. (2009). Nurturing generic capabilities through a teaching and learning environment which provides practise in their use. Higher Education, 57(1), 37-55.

Kubiatko, M., \& Vaculová, I. (2011). Project-based learning: characteristic and the experiences with application in the science subjects. Energy Education Science and Technology Part B: Social and Educational Studies, 3(1), 65-74.

Macho-Stadler, E., \& Elejalde-García, M. J. (2013). Case study of a problem-based learning course of physics in a telecommunications engineering degree. European Journal of Engineering Education, 38(4), 408-416.

Michael, J. (2006). Where's the evidence that active learning works? Advances in Physiology Education, 30(4), 159-167.

Pulko, S. H., \& Parikh, S. (2003). Teaching “soft” skills to engineers. International Journal of Electrical Engineering Education, 40(4), 243-254.

Ruizacárate Varela, C., García-García, M. J., González-García, C., \& Casado-Sánchez, J.L. (2013). Soft skills: a comparative analysis between online and classroom teaching. 2013 International Conference on Advanced Education Technology and Management Science AETMS, 359-366. 